\title{
PELATIHAN PEMBUATAN MEDIA EVALUASI DENGAN MENGGUNAKAN ISPRING DI SMA WISUDA KOTA PONTIANAK
}

\author{
Dochi Ramadhani ${ }^{1}$, Erni Fatmawati ${ }^{2}$, Dini Oktarika ${ }^{3}$ \\ ${ }^{1,2,3}$ Program Studi Pendidikan Teknologi Informasi dan Komputer Fakultas MIPA dan Teknologi \\ IKIP PGRI Pontianak, Jalan Ampera No. 88 \\ 1e_mail: dochi@gmail.com
}

\begin{abstract}
Abstrak
Tridharma dalam Perguruan Tinggi adalah melaksanakan Pendidikan, Penelitian, dan Pengabdian pada Masyarakat. Pada Semester Ganjil 2018/2019, kegiatan pengabdian pada masyarakat ditujukan kepada Guru di Sekolah Menengah Atas (SMA) WISUDA Kota Pontianak. Tujuan dari pengabdian pada masyarakat yang dilaksanakan oleh Program Studi Pendidikan Teknologi Informasi dan Komputer Institut Keguruan dan Ilmu Pendidikan Persatuan Guru Republik Indonesia (IKIPPGRI) Pontianak adalah untuk mengetahui respon guru setelah diberikan pelatihan pembuatan media evaluasi dengan menggunakan ispring. Metode pelaksanaan kegiatan dalam bentuk pelatihan, dilanjutkan dengan diskusi dan tanya jawab. Peserta pelatihan adalah seluruh Guru SMA Wisuda Kota Pontianak. Hasil pelatihan menunjukkan bahwa guru sangat tertarik dalam membuat media evaluasi dengan menggunakan ispring. Terdapat beberapa orang guru yang masih mengalami kesulitan dalam mengikuti pelatihan dikarenakan belum menguasai penggunaan perangkat komputer. Kesimpulan yang dapat diambil dari keseluruhan pelaksanaan pengabdian kepada masyarakat yang dilaksankan di SMA Wisuda Kota Pontianak menunjukkan adanya respon yang sangat baik, yang ditunjukkan oleh seluruh peserta pelatihan.
\end{abstract}

Kata kunci: Pelatihan, Media, Evaluasi, Ispring.

\begin{abstract}
Tridharma in Higher Education is implementing Education, Research, and Community Service. In the Odd Semester 2018/2019, community service activities were aimed at Teachers at the WISUDA High School in the City of Pontianak. The purpose of community service carried out by the Information Technology and Computer Education Study Program of the Teacher Training and Education Institute of the Republic of Indonesia Teachers Association (IKIP-PGRI) Pontianak was to find out the teacher's response after being given training in making evaluation media using ispring. The method of carrying out activities in the form of training, followed by discussion and question and answer. The training participants were all Pontianak Graduation High School Teachers. The training results show that the teacher is very interested in making evaluation media using ispring. There are some teachers who still experience difficulties in training because they have not mastered the use of computer devices. The conclusions that can be drawn from the overall implementation of community service carried out at the Pontianak City Graduation Senior High School indicate a very good response, which was shown by all trainees.
\end{abstract}

Keywords: Training, Media, Evaluation, Ispring. 


\section{PENDAHULUAN}

Bagi seorang pendidik kebutuhan akan penguasaan teknologi merupakan hal yang harus dikuasai guna mendukung proses pembelajaran, agar tujuan pendidikan pada umumnya dapat tercapai yaitu mencerdaskan kehidupan bangsa. Meningkatkan hasil belajar adalah aspek yang perlu diperhatikan yaitu proses pembelajaran yang terjadi di dalam kelas. Teknologi merupakan sebuah disiplin ilmu yang fokus mengatasi segala permasalahan dalam pendidikan sehingga dapat tercapai apa yang menjadi tujuan pendidikan melalui kawasan atau ruang lingkup desain, pengembangan, pemanfaatan, pengelolaan, dan penilaian (Sheel \& Richey, 1994). Secara lebih konkrit ruang lingkup desain, permasalahan dalam pendidikan dapat diselesaikan dengan melakukan pendesainan ulang kurikulum. Secara historis, bidang tersebut disebut baik sebagai Teknologi Pembelajaran ataupun sebagai Teknologi Pembelajaran. Bagi mereka yang beranggapan bahwa Pendidikan lebih tepat digunakan merujuk pada aneka ragam lingkungan belajar, termasuk belajar di rumah, di sekolah, maupun di tempat kerja. Sedangkan bagi mereka yang beranggapan dengan kata Pembelajaran merujuk pada hal-hal yang berkaitan dengan lingkungan sekolah saja (Sheel \& Rickey, 1994: 3). Guru sebagai fasilitator pembelajaran hendaknya mencari solusi bagaimana caranya, media evaluasi apa yang harus digunakan agar proses belajar mengajar dapat berjalan dengan menyenangkan dan dapat memudahkan siswa dalam menerima materi. Media evaluasi sebagai sumber belajar merupakan suatu komponen system pembelajaran yang meliputi pesan, orang, bahan, alat, teknik, dan lingkungan, yang dapat mempengaruhi hasil belajar peserta didik. Pentingnya guru-guru diberikan diberikan pelatihan tentang pemahaman dan keahlian kompetensi dalam pembuatan media evaluasi.

Menurut Hamalik dalam Arsyad (2008:15) bahwa "pemakaian media evaluasi dalam proses pembelajaran dapat membangkitkan keinginan dan minat yang baru, membangkitkan motivasi dan rangsangan kegiatan belajar, dan bahkan membawa pengaruh-pengaruh psikologi terhadap siswa". Oleh karena itu tujuan pengajaran dapat dijadikan sebagai acuan untuk menggunakan media. Media adalah suatu tampilan yang menggabungkan antara media teks, grafik dan suara 
dalam suatu aktifitas penggerak. Sebagai satu teknologi yang dapat menjadikan gambar yang diam menjadi gerak kelihatan seolah-olah gambar tersebut hidup, dapat bergerak beraksi dan berkata. adalah suatu proses dalam menciptakan efek gerakan atau perubahan dalam jangka waktu tertentu, dapat juga berupa perubahan warna dari suatu objek dalan jangka waktu tertentu dan bisa juga dikatakan berupa perubahan bentuk dari suatu objek ke objek lainnya dalam jangka waktu tertentu (Bustaman, 2001:32-33). Menurut Heinich (dalam Rusman, 2013:159), media merupakan alat saluran komunikasi. Media berasal dari bahasa Latin dan merupakan bentuk jamak dari kata "medium" yang secara harfiah berarti "perantara" yaitu perantara sumber pesan (a source) dengan penerima pesan (a receiver). Media tersebut bisa dipertimbangkan sebagai media pembelajaran jika membawa pesan-pesan (messages) dalam rangka mencapai tujuan pembelajaran. Dalam hal ini terlihat adanya hubungan antara media dengan pesan dan metode (methods). Yamin (2009:176) mengatakan media dalam komunikasi merupakan bagian dari komponen yang tidak dapat tidak mesti ada, yaitu; komunikator, komunikan, pesan, dan media yang saling terintegrasi. Sementara itu menurut Rusman (2013:160) media pembelajaran merupakan suatu teknologi pembawa pesan yang dapat digunakan untuk keperluan pembelajaran; media pembelajaran merupakan sarana fisik untuk menyampaikan materi pelajaran. Media pembelajaran merupakan saran komunikasi dalam bentuk cetak maupun pandang dengar termasuk teknologi perangkat keras.Berdasarkan beberapa pandangan yang ada di atas dapat disimpulkan bahwa media merupakan alat/perantara yang dapat digunakan untuk menyajikan materi serta membawa pesan sehingga memungkinkan siswa untuk mengerti dan memahami sesuatu dengan mudah dalam waktu yang relatif lama dibandingkan dengan penyampaian suatu materi yang hanya disajikan dalam bentuk ceramah tanpa bantuan alat bantu maupun media pembelajaran.

Kemp dan Dayton (dalam Arsyad, 2011:19) menyatakan bahwa Media pembelajaran dapat memenuhi tiga fungsi utama apabila media itu digunakan untuk perorangan, kelompok, atau kelompok pendengar yang besar jumlahnya, 
yaitu (a) memotivasi minat atau tindakan, (b) menyajikan informasi, dan (c) memberi instruksi. Sementara Menurut Azhar Arsyad (2011:15) fungsi utama media pembelajaran adalah sebagai alat bantu mengajar yang turut mempengaruhi iklim, kondisi, dan lingkungan belajar yang ditata dan diciptakan oleh guru. Selama ini media evaluasi digunakan untuk dua alasan. Pertama, untuk menarik perhatian siswa dan memperkuat motivasi. Jenis ini biasanya berupa tulisan atau gambar yang bergerak-gerak, yang lucu, aneh yang sekiranya akan menarik perhatian siswa. Hal ini biasanya tidak ada hubungan dengan materi yang akan diberikan kepada murid. Fungsi yang kedua adalah sebagai sarana untuk memberikan pemahaman kepada murid atas materi yang akan diberikan (Utami, 2007).

Melihat kenyataan yang diuraikan di atas, tampaknya perlu dilakukan suatu kegiatan yang mampu meningkatkan pemahaman dan keterampilan para guru dalam mengembangkan profesionalismenya, khususnya dalam pengembangan media evaluasi menggunakan ispring. iSpring merupakan perangkat untuk membuat media pembelajaran yang bersifat presentasi yang dapat digunakan dalam proses pembelajaran yang memuat aspek media pada audio, visual, audio visual, dan beragam jenis evaluasi yang sudah disediakan. Selain itu, iSpring dapat mengkonversi file powerpoint menjadi bentuk flash yang aktraktif sehingga user dapat menggunakannya baik secara langsung maupun dioptimalkan untuk pembelajaran dalam bentuk e-learning. berinteraksi langsung terhadap materi yang disampaikan ditambah dengan materi-materi pokok dalam powerpoint. Ispring yang biasa digunakan salah satunya untuk membuat media evaluasi dengan soal-soal yang interaktif dengan menggunakan iSpring yang dipadukan dengan beberapa software pendukung sehingga pada media yang dikemas tersebut memuat tampilan yang lebih menarik yang disertai dengan audio visual bersamaan dengan slide power point serta terdapat beragam jenis evaluasi sehingga siswa dapat diarahkan untuk lebih fokus dan diajak berinteraksi dengan sesama sehingga penggunaan media iSpring lebih maksimal serta siswa lebih mudah untuk menangkap dan memahami materi belajar menggunakan media tersebut. Selain itu media iSpring juga dapat 
membantu guru agar lebih mudah dalam menerangkan materi pelajaran dan mengkondisikan suasana siswa yang kondusif tanpa mengambil alih peran utama guru sebagai pengajar. Kegiatan pengabdian pada masyarakat (PPM) ini akan dilakukan di SMA Wisuda Kota Pontianak. Khalayak yang menjadi sasaran kegiatan ini adalah seluruh guru SMA Wisuda Pontianak. Kegiatan PPM yang diusulkan ini menekankan pada kemampuan dan keterampilan para guru dalam dalam mebuat media evaluasi dengan menggunakan ispring. Dengan pelatihan tersebut diharapkan guru mampu dalam membuat media evaluasi menggunakan ispring yang menarik dan dapat menunjang dalam proses pembelajaran di kelas.

iSpring adalah adalah alat yang memberikan beberapa fitur pada power poiny yang di dalamnya termasuk terdapat karakter simulasi dialog yang realistik dengan tambahan fitur evaluasi penilaian. Hasil dari pembuatan media pembelajaran menggunakan iSpring dapat dikonversikan dalam bentuk format flash, power point, HTML5, dan MP4 video, atau bahkan bisa dijadikan sebagai media berbasis mobile (Bauman, 2016).

iSpring memiliki berbagai kegunaan, di antaranya: 1) Dapat menyisipkan berbagai bentuk media diantaranya adalah dapat merekam suara, video presenter, video pembelajaran, menambahkan Flash dan video YouTube, mengimpor atau merekam audio, menambahkan informasi pembuat presentasi dan logo pendidikan, membuat materi dalam bentuk buku 3 dimensi, serta membuat navigasi dan desain yang menarik; 2) Mudah dikonvert dalam format flash tanpa harus membuatnya dari software adobe flash player, serta dapat juga dipublish di halaman web secara offline; 3) Dapat membuat kuis dengan beragam jenis pertanyaan/soal yang menarik, seperti : True/False, Multiple Choice, Multiple response, Type In, Matching, Sequence, numeric, Fill in the Blank, Multiple Choice Text; dan 4) Pembuatannya yang mudah dan hasil output yang tidak membutuhkan kapasitas besar sehingga tidak memberatkan laptop atau komputer.

iSpring bekerja sebagai add-ins PowerPoint sehingga penempatan iSpring ada di dalam microsoft power point dengan kata lain peneliti juga menggunakan microsoft power point sebagai dasar pemberian materi-materi garis besarnya saja karena mengingat apabila menggunakan power point saja dirasa masih kurang 
interaktif. Software iSpring sudah banyak digunakan dalam berbagai bidang seperti bidang pemasaran, video simulasi, interaksi kursus, hingga pada pembelajaran di kelas. Hal ini dikarenakan proses pembuatannya yang mudah tetapi dapat menciptakan karya yang inovatif dan menarik.

\section{METODE PELAKSANAAN}

Pelatihan dilaksanakan di SMA Wisuda Kota Pontianak Provinsi Kalimantan Barat. Pelaksanaan kegiatan pelatihan merupakan salah satu bentuk kegiatan pengabdian pada masyarakat yang merupakan bentuk pelaksanaan dari Tridharma Perguruan Tinggi. Kegiatan ini merupakan keagenda tahunan dosen Program Studi Pendidikan Teknologi Informasi dan Komputer (PTIK).

Peserta pelatihan adalah seluruh guru SMA Wisuda Kota Pontianak. Kegiatan pelatihan dilaksanakan di Aula SMA Wisuda Kota Pontianak. Alat dan bahan yang digunakan sebagai penunjang kegiatan terdiri dari projektor, laptop, meja, kursi, microfon, whiteboard, spidol, dan alat penunjang lainnya. Seluruh guru yang menjadi peserta pelatihan diberi seminar kits yang terdiri dari alat tulis dan materi pelatihan.

Metode yang digunakan didalam penyampaian materi pelatihan terdiri dari metode demostrasi, ceramah, diskusi, dan tanya jawab. Metode demonstrasi digunakan untuk menunjukkan langkah-langkah dalam membuat media evaluasi menggunakan Ispring. Metode ceramah digunakan untuk memaparkan materi tentang media dan applikasi yang dapat digunakan untuk membuat media evaluasi menggunaka Ispring. Metode diskusi digunakan untuk meningkatkan aktivitas guru di dalam pemecahan masalah bersama selama kegiatan pelatihan berlangsung. Tanya jawab dilakukan agar guru dapat menyampaikan pertanyaan terutama yang memiliki kaitan dengan tema yang diambil untuk kegiatan pelatihan.

\section{HASIL DAN PEMBAHASAN}

Pelaksanaan kegiatan pengabdian kepada masyrakat ini dimulai dari tahap persiapan terlebih dahulu. Kegiatan ini dilaksanakan dengan bermitra bersama 
Guru-guru SMA Wisuda Pontianak, dan ada beberapa sekolah yang juga ikut serta dalam kegiatan ini. PPM bertema pelatihan pembuatan media evaluasi menggunakan ispring bagi guru-guru yang berada dilingkungan SMA Wisuda Kota Pontianak.

Pemilihan Ispring di dalam pelatihan ini didasarkan pada penelitian yang pernah dilaksanakan oleh Kusuma, Mustami, dan Jumadi yang berjudul Pengembangan media pembelajaran interaktif Power Point Ispring Suite 8 pada konsep sistem ekskresi di Sekolah Menengah Atas. Berdasarkan data yang diperoleh, pembelajaran dengan media pembelajaran interaktif Power Point Ispring Suite 8 memiliki nilai kepraktisan yang baik. Hasil respon guru menunjukkan nilai rata-rata respon di angka 4.67 dengan presentase 93,40\% dengan kategori sangat kuat.

Kegiatan persiapan PPM dilaksanakan dengan melalui beberapa tahap yaitu: kegiatan persiapan meliputi koordinasi, penyiapan alat bahan, publikasi, dan periapan lainnya. Sebelum pelaksanaan pelatihan, Dosen Program Studi Pendidikan Teknologi Informasi dan Komputer (Prodi PTIK) mengadakan observasi dan melakukan koordinasi dengan pihak SMA Wisuda Pontianak. Pertemuan ini membahas tentang: rencana umum, rencana teknis (waktu dan tempat pelaksanaan kegiatan, peserta yang mengikuti kegiatan ini serta perangkat apa saja yang dibutuhkan).

Setelah diperoleh kesepakatan untuk pelaksanaan kegiatan, dosen Prodi PTIK mempersiapkan materi dan peralatan terkait pelatihan pembuatan media evaluasi menggunakan ispring. Hal-hal yang dipersiapkan meliputi modul pelatihan, serifikat, nama-nama guru yang akan menjadi peserta. Secara rinci, langkah-langkah yang dilakukan dalam pelaksanaan kegiatan ini yatu: 1) Mulai dari melakukan observasi lapangan untuk memperoleh data awal tentang permasalahan yang dihadapi pihak sekolah, 2) Melakukan analisis kebutuhan sekolah dan menawarkan solusi penyelesaian, 3) Membuat materi yang berkenaan dengan materi pelatihan pembuatan media evaluasi menggunakan ispring, 4) Melakukan pelatihan pembuatan media evaluasi berbasis mengguanakan ispring, dan 5) Melakukan pendampingan selama pelaksanaan kegiatan kepada guru-guru 
SMA Wisuda Pontianak. Adapun jadwal pelaksanaan kegiatan dapat dilihat pada tabel 1 .

\begin{tabular}{|c|l|}
\hline Waktu & \multicolumn{1}{|c|}{ Materi } \\
\hline $07.30-08.00$ & Pembukaan \\
\hline $08.00-.11: 40$ & Pembuatan media evaluasi Ispring sesi 1. \\
\hline 13:00-14.30 & Pembuatan media evaluasi Ispring sesi 2. \\
\hline $14: 30$ & Penutup \\
\hline
\end{tabular}

Tabel 1. Jadwal Pelaksanaan PPM

Kegiatan PPM ini dilaksanakan sebanyak 1 kali pertemuan. Pertemuan pertama dilaksanakan pada hari Sabtu tanggal 15 September 2018. Tempat pelaksanaan diadakan di Aula SMA Wisuda. Peserta pelatihan pembuatan media evaluasi menggunakan ispring dapat dilihat pada gambar 1 .

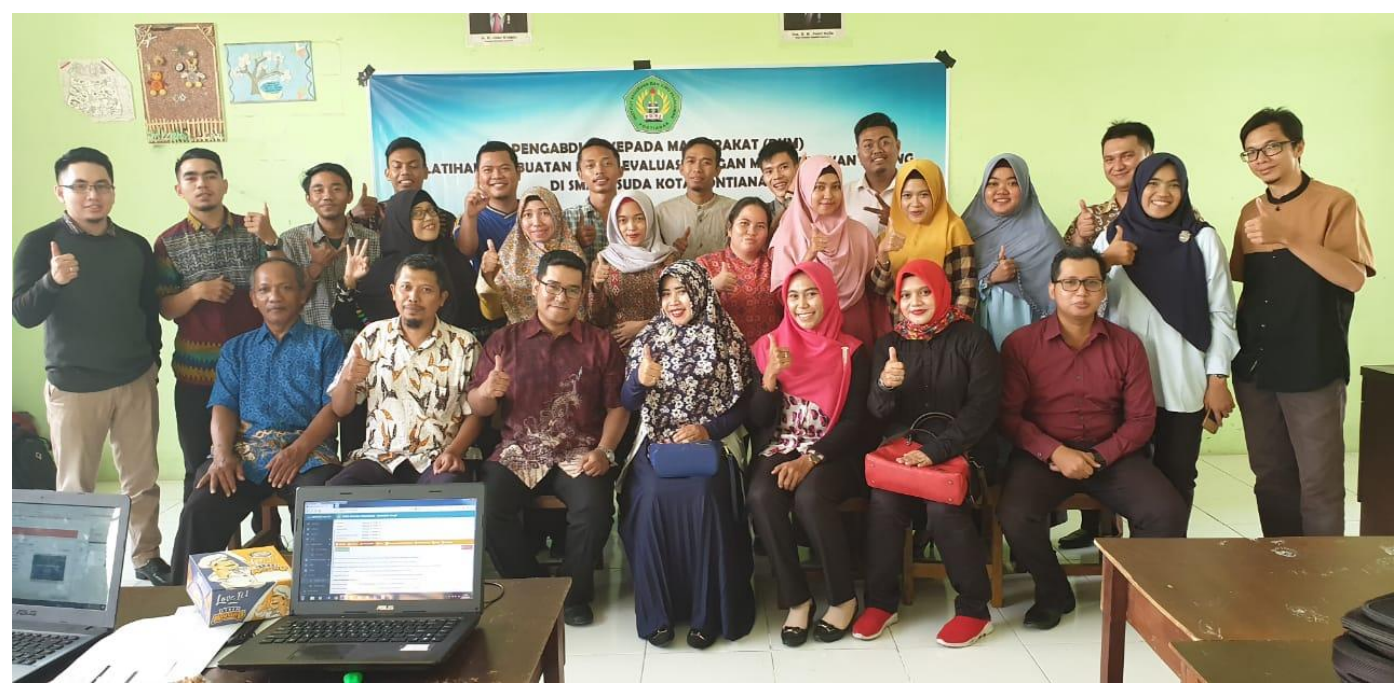

Gambar 1. Peserta Pelatihan Pembuatan Media Evaluasi Menggunakan Ispring

Pelaksanaan pelatihan berjalan dengan baik dan lancar. Pelatihan pembuatan media evaluasi menggunakan Ispring memberikan manfaat bagi peserta. Hal ini sesuai dengan penelitian yang pernah dilaksanakan oleh Dian Wulandari yang berjudul Pengembangan Multimedia Pembelajaran Interaktif Berbasis Power Point iSpring Presenter pada Mata Pelajaran Teknologi Informasi dan Komunikasi (TIK) untuk SMA. Hasil penelitian menunjukkan bahwa media pembelajaran iSpring dikatakan layak sebagai media pembelajaran interaktif. Hal tersebut dibuktikan dengan nilai kevalidan media iSpring dengan nilai rata-rata 85,6. Varibel materi/isi yang diujikan kepada ahli media sudah dinyatakan valid dengan 
nilai $84,0 \%$ yang tergolong tinggi dengan pemenuhan $\mathrm{SK}, \mathrm{KD}$, dan indikator yang sesuai dengan KTSP. Di samping itu, hasil analisis uji praktikalitas media iSpring dinyatakan berkategori praktis oleh siswa dengan nilai rata-rata 86,5\%.

Adapun hambatan-hambatan yang ditemukan dalam pelaksanaan PPM di SMA Wisuda Pontianak yaitu: 1) Hambatan dalam menjelaskan materi pembuatan media evaluasi menggunakan ispring kepada guru-guru harus pelanpelan karena sebagain peserta tergolong guru senior yang belum terlalu mahir dalam membuat media evaluasi, dan 2) Guru-guru masih asing dengan media evaluasi menggunakan ispring, sehingga contoh yang dapat ditunjukan hanya bisa contoh sederhana saja, dikarenakan guru-guru masih awam.

\section{SIMPULAN}

Berdasarkan hasil dari kegiatan pengabdian masyarakat di SMA Wisuda Pontianak berupa pelatihan pembuatan media evaluasi menggunakan ispring, diperoleh hasil yaitu: 1) Pelaksanaan kegitan pengabdian kepada masyarakat ini terselenggara dengan baik, berjalan lancar, guru-guru memiliki antusias yang luar biasa sepanjang kegiatan berlangsung, 2) Guru-guru aktif dalam membuat media evaluasi dengan menggunakan ispring, 3) Guru-guru mendapatkan keterampilan baru dalam pembuatan media evaluasi menggunakan Ispring, sehingga dapat diimplementasikan selama proses pembelajaran yang dapat memudahkan guru dalam mengajar, sehingga dapat meningkatkan kualitas pembelajaran di kelas, 4) Pelaksanaan kegitan pengabdian kepada masyarakat ini terselenggara dengan sangat baik dan berjalan lancar, dan 5) Guru-guru menjadi termotivasi untuk membuat media pembelajaran yang relevan dengan masing- masing bidang keilmuan.

\section{DAFTAR PUSTAKA}

Arsyad, A. (2011). Media Pembelajaran. Jakarta: Raja Grafindo Persada.

Barbara, B \& Richey Rita C. 1994. Teknologi Pembelajaran Definisi dan Kawasannya. Jakarta: Unit Percetakan UNJ. 
Bustaman, B. 2001. Web design dengan macromedia flash mx 2004. Yogyakarta: Andi Offset.

Kusuma, N.R., Mustami, M.K. Jumadi, O. 2018. Pengembangan Media Pembelajaran Interaktif Power Point Ispring Suite 8 Pada Konsep Sistem Ekskresi Di Sekolah Menengah Atas. Jurnal UNM, Vol. IV, No. 1 (7-13).

Rusman. 2013. Belajar dan Pembelajaran Berbasis Komputer. Bandung : Alfabeta.

Utami, D. 2007. dalam Pembelajaran. www.uny.ac.id/akademik/default.php.

Wulandari, D. 2013. Pengembangan Multimedia Pembelajaran Interaktif Berbasis Power Point iSpring Presenter pada Mata Pelajaran Teknologi Informasi dan Komunikasi (TIK) untuk SMA. Vol 1, No. 1 (2014).

Yamin, H.M. 2009. Desain Pembelajaran Berbasis Tingkat Satuan Pendidikan. Jakarta: Gaung Persada Press Jakarta 